\title{
Extensive Hypoplasia of Permanent Dentition Due to Childhood Illness and Antibiotic Use- A Case Report
}

\section{Mauli Simratvir*}

Assistant Professor, Department of Pediatric Dentistry, S.K.S.S. Dental College, India

\begin{abstract}
Background: Changes in environment during apposition and maturation stage of amelogenesis results in defective formation of enamel. This paper reports a case of extensive hypoplasia of permanent dentition due to childhood illness and antibiotic use.

Case description: A 9 year old patient reported with extensive Enamel hypoplasia on all erupted and unerupted permanent teeth the cause of which could only be related to frequent Upper Respiratory Tract Infection (URTI) and Cephalosporins and Paracetamol intake for the same on and off almost for a period of 1 to 4 years. To restore esthetics intermittent treatment consisted of composite build up of anterior teeth with special care on bonding.

Clinical implications: Apart from aesthetic and functional problems, the psychological problem of disfigured dentition is considerable in children. Thus risks and benefits should be carefully weighed before indiscriminate prolonged use of any antibiotic in children.
\end{abstract}

Keywords: Hypoplasia, Permanent dentition, Antibiotic

\section{Introduction}

Teeth develop as a result of series of inductive sequential and reciprocal interaction between the ectoderm and the subjacent mesenchyme [1]. Although the development is genetically regulated but it is also sensitive to environmental disturbances.

Basic scientific research is increasingly demonstrating that ameloblasts are highly susceptible to relatively minor changes in their environment for e.g. increase in temperature [2], hypocalcemia [3] and $\mathrm{pH}$ levels [4]. Various inborn errors of metabolism, hypocalcemia, prematurity, irradiation, fever, allergy, immunization, infection, nutritional deficiencies, intoxication, endocrinopathies may disturb the forming enamel.

Aberrations in the function of tooth forming cells lead to permanent morphological consequences. DDE (Developmental defects of Enamel) present in a spectrum of severity ranging from a change in translucency, also known as enamel opacity to reduction or loss of enamel known as enamel hypoplasia. Injury encountered during the early stages of enamel formation are thought to result in Enamel Hypoplasia $(\mathrm{EH})$ where as those resulting during later or more mature stages cause Enamel Opacity (EO) $[5,6]$. The extent of enamel defects varies from accentuated incremental lines of Retzius to complete absence of enamel and depends upon the intensity and duration of etiological factors .

Damage to enamel is most likely caused by the infective agents affecting the ameloblasts directly or with elevated temperatures associated with infections. Childhood infections are associated with intake of antibiotics. There is still debate on as to the illness or antibiotics are responsible for enamel hypoplasia [7].

This paper reports a case with enamel hypoplasia affecting the whole dentition.

\section{Case Report}

A nine year old girl reported to the department with chief complaint of disfigured anterior teeth. Patient had noted yellowing of teeth since the time permanent teeth had started erupting. Past medical history revealed the patient had been hospitalised because of respiratory tract infection at about 1.6 years of age. Details revealed that child had recurrent fever and running nose diagnosed as Upper Respiratory Tract Infection (Streptococcal). The child was administered Cephalosporins (Dispersible 50mg tablet twice daily) and Paracetamol (dose of between $60 \mathrm{mg}$ and $120 \mathrm{mg}$ i.e. $2.5 \mathrm{~mL}$ to $5 \mathrm{~mL}$ of paracetamol liquid (oral suspension) at strength of $120 \mathrm{mg} / 5 \mathrm{~mL}$ every $4-6$ hours) for the same. Due to frequent relapse the drugs were self administered by parents on and off almost for a period of 1 to 4 years. Family history did not reveal any genetic links. The child's sibling and parents reported a normal dentition without any evidence of enamel hypoplasia or enamel opacities. Birth history revealed normal delivery; mother denied any use of medication during pregnancy. The child was weaned by 6 months of age.

Clinical examination revealed grossly decayed first permanent molars 26, 36 and 46. 16 showed evidence of EO on occlusal one third. $12,11,21,32,31,41,42$ showed a very thin almost non-existent layer of enamel in the incisal and middle thirds. (Figure 1) In the cervical area of erupted anterior teeth the enamel thickness seemed to be normal. Erupted 24 showed area of hypoplasia on the occlusal one third. The deciduous canines and molars showed normal morphology and mineralisation pattern.

There were no associated systemic manifestations ruling out any syndromic condition.

Radiographic examination revealed missing 22. The incisal and occlusal aspects of developing canines and premolars looked comparatively radiolucent suggestive of hypoplastic enamel (Figure 2).

*Corresponding author: Mauli Simratvir, MDS, Assistant Professor, Department of Pediatric Dentistry, S.K.S.S. Dental College, Sarabha, Ludhiana, India, Tel: 09356991691; Fax: 0161-2424040; E-mail: dr_maulisimrat@yahoo.com

Received May 18, 2011; Accepted November 05, 2011; Published November 10, 2011

Citation: Simratvir M (2011) Extensive Hypoplasia of Permanent Dentition Due to Childhood Illness and Antibiotic Use- A Case Report. Dentistry 1:107. doi:10.4172/2161-1122.1000107

Copyright: (C) 2011 Simratvir M. This is an open-access article distributed under the terms of the Creative Commons Attribution License, which permits unrestricted use, distribution, and reproduction in any medium, provided the original author and source are credited. 
The case was provisionally diagnosed to be that of enamel hypoplasia the causative factors of which were linked to childhood illness and prolonged use of antibiotics.

\section{Treatment plan}

Treatment was instituted under local anaesthesia.

Intermittent treatment consisted of composite build up of anterior teeth with special care on bonding. To ensure removal of excess protein as in case of hypoplastic teeth sodium hypochlorite treatment of the affected teeth was done.

Molars were endodontically treated. Complete pain control during treatment was obtained by using combination of intra-pupal and regional nerve block. Intermittent restoration was done with Stainless steel crowns (Figure 3).

Patient was given oral hygiene instructions and advised regular recall visits for monitoring newly erupted teeth. Once the growth would be complete and permanent dentition established, placement of ceramic crowns would be the treatment of choice.

\section{Discussion}

Alteration in genetic pattern and environmental disturbances

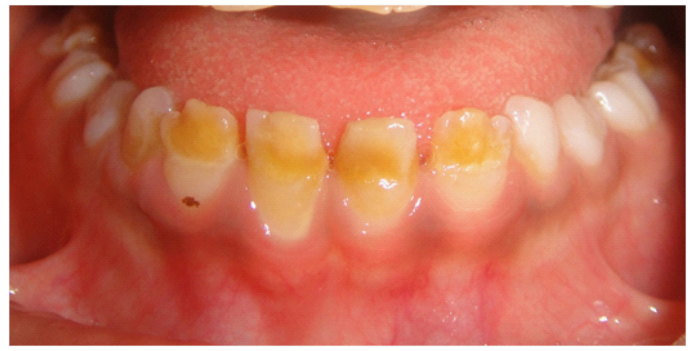

Figure 1: Intraoral photograph showing hypoplastic 36, 32, 31,41,42,46.

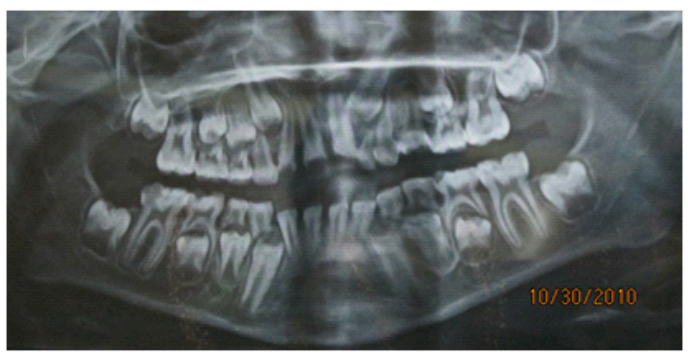

Figure 2: Orthopantamograph of patient showing reduced radio-opacity suggestive of hypoplastic teeth.
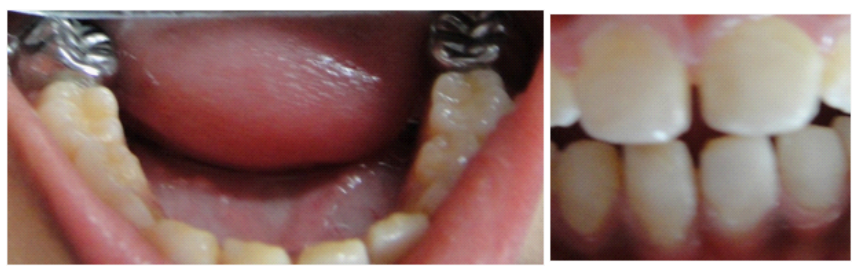

Figure 3: Intraoral photograph showing composite restoration wrt anterior teeth and stainless steel crowns wrt 36,46. during amelogenesis may disrupt the mechanism of apposition and maturation of enamel. The change in genotype manifests as altered formation of enamel in both the permanent and primary dentition (Amelogenesis imperfecta), while environmental disturbances manifest as hypoplasia/opacity specific to the time when insult occurs.

However in our case Amelogenesis imperfecta was ruled out as the primary dentition was unaffected. That the dental manifestation was due to exposure to excessive fluoride also could not have been a possibility as child's sibling who was 1 year younger showed a healthy dentition and the family resided in low fluoride region. Moreover clinically, the defects of fluorosis are evident through out the enamel as diffuse opacities whereas environmental hypoplasia affects a localised thickness of enamel presenting as demarcated opacities.

Hypoplasia in mandibular molars could not be ascertained as they were already decayed by the time of examination. Maxillary molars showed EO, have a greater tendency to escape caries as compared to permanent molars due to their later eruption. Jalevik [8] explained the fact that the defects were not uniform on the first permanent molars (FMP) as it is possible that groups of ameloblasts are active at different times during amelogenesis of individual FMPs, explaining the asymmetry of defects and defect severity in affected dentitions.

Crombe [9] in their study evaluated the exposure to environmental contaminants such as PCBs and dioxins, peri- and neonatal problems, fluoride exposure as causative factors for MIH but found insufficient evidence to reach conclusive etiology.

PCBs (polychlorinated biphenyls ) and dioxins could not have contributed much to the etiology in our case as the child was weaned off by 6 months of age. Alaluusua [10] found a correlation between prolonged breast feeding and hypo mineralisation of first molars and claimed that environmental contaminants like dioxin were interfering with tooth development. In their study the median duration of breast feeding was 12 months; and no child with defects had been breast fed for less than eight months.

Respiratory problems and otitis media are the most consistently implicated in the etiology of hypoplasia, although other conditions and medications have been reported to be related to dental defects. Hong [7] in their study suggested a link between amoxicillin use during infancy and developmental defects of enamel. Ford D [11] concluded that antibiotics contribute to the enamel changes associated with otitis media, although the risks are probably small compared to the effects of infective agents. The majority of authors acknowledge the possible confusion between, and confounding influence of, the effect of disease itself as opposed to the effect of any treatment on dental development. The only possible etiology could be linked to frequent incidents of URTI and antibiotic intake which in this case was cephalosporin.

The reason why only the occlusal and not the cervical part of the enamel was affected in the incisor region could be that the insult only had the potential to disturb the ameloblast during the child's early years. Another possible explanation is that the thickness of the already formed enamel influenced the possibility for the ameloblasts to resist the insult [8].

One of the main challenges during treatment was that following administration of dental local anaesthetic, patient continued to experience pain on instrumentation or application of cold water or air. Failure to achieve adequate levels of pulpal analgesia may be attributable to peripheral sensitization. Recent work in hypoplastic 
Citation: Simratvir M (2011) Extensive Hypoplasia of Permanent Dentition Due to Childhood Illness and Antibiotic Use- A Case Report. Dentistry 1:107. doi:10.4172/2161-1122.1000107

permanent first molar has shown significant changes in the expression of a number of different neuropeptides as well as thermal vanilloid receptor TRPV1. An increase in expression of tetrado toxin resistant sodium channels has been linked to hyperalgesia and altered sensitivity to local anaesthesia [12].

\section{Conclusion}

This report presents a case of extensive enamel hypoplasia because of frequent childhood illness and prolonged antibiotic use. Apart from aesthetic and functional problems, the psychological problem is considerable in children. Thus risks and benefits should be carefully weighed before indiscriminate prolonged use of any antibiotic in children.

\section{References}

1. Thesleff I, Vaahtokari A, Partanen AM (1995) Regulation of organogenesis: common molecular mechanisms regulating the development of teeth and other organs. Int J dev Biol 39: 35-50.

2. Tung K, Fujita H, Yamashita $Y$, Takagi $Y$ (2006) Effect of turpentine induced fever during enamel formation of rat incisor. Arch Oral Biol 51: 464-470.

3. Yamaguti PM, Arana-Chavez VE, Acevedo AC (2005) Changes in amelogenesis in the rat incisor following short term hypocalcemia. Arch Oral Biol 50: 185-188.
4. Sui W, Boyd C, Wright JT (2003) Altered pH regulation during enamel development in the cystic fibrosis mouse incisor. J Dent Res 82: 388-392.

5. Suckling GW (1989) Developmental defects of enamel: Historical and present day perspectives of their pathogenesis. Adv Dent Res 3: 87-94.

6. Den Besten PK (1999) Mechanism and timing of fluoride effects on developing enamel. J Public Health Dent 59: 247-251.

7. Hong L, Levy SM, Warren JJ, Dawson DV, Bergus GR, et al. (2005) Association of amoxicillin use during early childhood with developmental tooth enamel defects. Arch Pediatr Adolesc Med 159: 943-948.

8. Jalevik B, Noren JG (2000) Enamel hypomineralisation of permanent first molars: a morphological study and survey of possible aetiological factors. Int $\mathrm{J}$ Paed Dent 10: 278-289.

9. Crombie F, Manton D, Kilpatrick N (2009) Aetiology of molar-incisor hypomineralistaion: a critical review. Int J Paed Dent 19: 73-83.

10. Alaluusua S, Lukinamaa PL, Koskimies M, Pirinem S, Holta P, et al. (1996) Development dental defects associated with Long breast feeding. European $J$ Oral Sci 104: 439-447.

11. Ford D, Seow WK, Kazoullis S, Holcombe T, Newman B (2009) A controlled study of risk factors for enamel hypoplasia in permanent dentition. Pediatr Dent 31: 382-388.

12. Rodd HD, Boisonnade FM, Day PF (2007) Pulpal status of hypomineralised permanent molars. Pediatric dent 29: 514-520. 